\title{
Symptoms and stool patterns in patients with ulcerative colitis
}

\author{
S S C RAO, C D HOLDSWORTH, AND N W READ \\ From the Gastrointestinal Unit, Royal Hallamshire Hospital, Sheffield
}

SUMMARY The prevalence of symptoms and stool patterns was assessed prospectively in 96 patients with ulcerative colitis subdivided according to the extent and activity of the disease. Increased frequency of defecation $(83 \%)$, urgency $(85 \%)$, a feeling of incomplete evacuation $(78 \%)$ and tenesmus $(63 \%)$ were the most frequent symptoms experienced by patients with active colitis. All were significantly more common $(p<0.001)$ in patients with active than quiescent colitis and their prevalence was similar in those with total and distal colitis, indicating that these symptoms are related to an inflamed and irritable distal colon. Twenty seven per cent of patients with active colitis voided hard stools indicative of constipation, however, and this was more common in active, than quiescent colitis $(\mathbf{p}<\mathbf{0} \cdot 05)$. This feature is probably secondary to faecal stasis in the proximal colon, and an apt description of the bowel disturbance in ulcerative colitis, irrespective of the extent of disease is that the colon suffers from proximal constipation and distal irritability.

For a condition in which change of bowel habit is a major manifestation, there is a surprising dearth of objective data on bowel symptoms in ulcerative colitis, and this is reflected by the very inadequate and poorly referenced accounts in many standard textbooks of medicine and gastroenterology. Although it is often assumed that the patient with active colitis usually has diarrhoea, there are no systematic studies of stool weight and frequency. Constipation has been mentioned in some clinical accounts $^{1-5}$ but many descriptions have ignored this symptom..$^{67}$ In a small series, Engel ${ }^{3}$ observed that $44 \%$ of colitics were constipated at the time of presentation, and in a larger retrospective enquiry, constipation was reported by $20 \%$ of patients. ${ }^{8}$ The concept of faecal stasis in colitis was extended by Lennard-Jones $e t a l,{ }^{910}$ and in a retrospective case record analysis it was estimated that $15 \%$ of colitics exhibited this feature. " During the course of physiological studies of patients with ulcerative colitis, we observed that transit through the small intestine and proximal colon was paradoxically slow, ${ }^{12}$ and this reinforced our own clinical impression that constipation is a frequent problem. In order to understand the nature of the bowel disturbance in patients with ulcerative colitis, we set out to systematically docu-

Address for correspondence: Dr C D Holdsworth, FRCP, Consultant Physician, Floor J, Royal Hallamshire Hospital, Sheffield S10 2JF

Received for publication 24 August 1987. ment the prevalence of symptoms and stool patterns in three patients.

\section{Methods}

PATIENTS

One hundred and ten assessments were carried out in 96 patients with histologically proven ulcerative colitis. The clinical details are shown in the Table. The disease was judged to be active, if sigmoidoscopic appearance and histology of a biopsy of rectal mucosa showed evidence of active inflammation and the severity of colitis was categorised in accordance with Truelove and Witts criteria. ${ }^{13}$ The extent of the disease was assessed by radiology and sigmoidoscopy and was termed distal if it did not extend proximal to the splenic flexure. Sixty patients had active colitis and 50 had quiescent colitis and 14 were assessed during active and quiescent phases of their disease. Of patients with distal colitis, four with active disease and three with quiescent disease had proctitis only. Of the 26 patients with active total colitis, five had mild colitis, 10 moderately severe colitis and 11 severe colitis. Of the 34 patients with active distal colitis, 12 had mild colitis, 16 moderately severe colitis and six severe colitis.

SYMPTOM QUESTIONNAIRE

All patients completed a symptom questionnaire in 
Table 1 Clinical details and the prevalence of stool patterns and bowel symptoms, in patients with ulcerative colitis, subdivided according to the extent and activity of disease

\begin{tabular}{|c|c|c|c|c|}
\hline & \multicolumn{2}{|l|}{ Total colitis } & \multicolumn{2}{|l|}{ Distal colitis } \\
\hline & Active & Quiescent & Active & Quiescent \\
\hline Studied (n) & 26 & 19 & 34 & 31 \\
\hline Men/women & $10 / 16$ & $9 / 10$ & $19 / 15$ & $13 / 18$ \\
\hline Age (years)* & $48(19-76)$ & $50(20-79)$ & $46(20-79)$ & $48(20-80)$ \\
\hline Duration of colitis (years)* & $7(0 \cdot 5-21)$ & $8(0 \cdot 6-22)$ & $6(0 \cdot 4-22)$ & $8(0 \cdot 6-23)$ \\
\hline Daily stool frequency* & $5(4-9) \dagger$ & $2(1-3)$ & $4(2-6) \ddagger$ & $1(1-3)$ \\
\hline Nocturnal defecation & $21(81 \%) \dagger$ & 0 & $19(56 \%) \ddagger$ & 0 \\
\hline \multicolumn{5}{|l|}{ Predominant stool consistency } \\
\hline Unformed & $17(65 \%) \dagger$ & $3(16 \%)$ & $15(44 \%) \ddagger$ & $2(7 \%)$ \\
\hline Formed & $4(15 \%) \dagger$ & $15(79 \%)$ & $8(23 \%) \ddagger$ & $26(84 \%)$ \\
\hline Hard & $5(19 \%)$ & $1(5 \%) \mathrm{NS}$ & $11(33 \%) \S$ & $3(9 \%)$ \\
\hline \multicolumn{5}{|l|}{ Symptoms } \\
\hline Urgency & $24(92 \%) \dagger$ & $2(11 \%)$ & $27(79 \%) \ddagger$ & $5(16 \%)$ \\
\hline Incomplete evacuation & $20(77 \%) \dagger$ & $3(16 \%)$ & $27(79 \%) \ddagger$ & $6(19 \%)$ \\
\hline Tenesmus & $18(69 \%) \dagger$ & $2(11 \%)$ & $20(59 \%) \ddagger$ & $3(10 \%)$ \\
\hline Pain & $12(46 \%) \dagger$ & $2(11 \%)$ & $18(53 \%) \ddagger$ & $5(16 \%)$ \\
\hline Anal soreness & $13(50 \%) \dagger$ & $2(11 \%)$ & $11(32 \%) \ddagger$ & $2(6 \%)$ \\
\hline Incontinence & $8(31 \%) \dagger$ & 0 & $6(18 \%) \ddagger$ & 0 \\
\hline
\end{tabular}

${ }^{*}=$ data expressed as median (range); $\dagger=$ significantly different from quiescent total colitis $(p<0 \cdot 01) ; \ddagger=$ significantly different from quiescent distal colitis $(p<0 \cdot 01) ; \S=$ significantly different from quiescent distal colitis $(p<0 \cdot 05)$; NS=not significant.

which they indicated the presence or absence of six symptoms related to defecation. These were: (1) urgency (an irresistible and urgent desire to defecate), (2) feeling of incomplete evacuation (a strong and persistent desire to evacuate after defecation), (3) tenesmus (continual inclination to evacuate bowels accompanied by painful straining), (4) pain (lower abdominal or rectal pain, with or without any relation to defecation), (5) perianal soreness (intense discomfort or itching of the perianal skin), (6) faecal incontinence (inability to control defecation voluntarily resulting in leakage of motions and/or soiling of garments). A clear explanation of each symptom was provided at the time of the interview.

In addition, all patients were asked if their stools were predominantly loose, formed or hard, if they were associated with blood and mucus, and if they had to wake up at night to defecate. Their average daily bowel frequency was also recorded.

STATISTICAL ANALYSIS

The differences in the stool consistency and in the prevalence of symptoms between active and quiescent disease were analysed using $\chi^{2}$ tests. Data on stool frequency were compared by Wilcoxon's rank-sum tests.

\section{Results}

PREVALENCE OF SYMPTOMS

The prevalence of the six bowel symptoms in patients with ulcerative colitis is shown in the Table. Patients with active disease exhibited a higher prevalence of urgency, a feeling of incomplete evacuation, tenesmus, pain, anal soreness and faecal incontinence, compared with patients with quiescent colitis. The prevalence of these symptoms did not vary significantly with the extent of the disease (Table). Fourteen patients (women=12, men=two) with active colitis reported faecal incontinence. All except two (one woman, one man) were over 60 years of age.

\section{STOOL PATTERNS}

As would be expected, the frequency of defecation was higher in patients with active than quiescent colitis, irrespective of the extent of the disease (Table). Eighty three per cent of patients with active colitis were defecating more than three times a day. No patient with quiescent colitis experienced this degree of stool frequency. Nocturnal defecation was reported by $81 \%$ of patients with active total colitis and $56 \%$ of patients with active distal colitis, but by none of the patients with quiescent colitis. There was no significant difference in the prevalence of nocturnal defecation between patients with total and distal colitis.

Ninety six per cent of patients with active colitis passed blood and mucus in their stools every day. In contrast only $8 \%$ of patients with quiescent disease occasionally passed blood and $12 \%$ occasionally passed mucus in their stools. 
Although the proportion of stools which were unformed was significantly higher in patients with active than quiescent colitis (Table), many patients with active disease passed formed or hard stools.

A higher proportion of patients with active colitis $(27 \%)$ than quiescent colitis $(8 \%)$ reported that their stools were hard $(\mathrm{p}<0.05)$, and this was true in both distal colitis and total colitis, although in the case of total colitis this did not reach statistical significance (Table). Two of four patients with active proctitis and one of three with quiescent proctitis voided hard stools. The hard stools of active colitis were always accompanied by blood and mucus and were associated with symptoms of tenesmus and a feeling of incomplete evacuation.

\section{Discussion}

Although most patients with active colitis had increased stool frequency and were voiding blood and mucus in their stools, the results of stool consistency were surprising. Twenty eight of 60 $(47 \%)$ patients with active colitis reported they were passing formed stools and in as many as $16(27 \%)$ patients, the stools were hard. This shows that liquid diarrhoea is by no means a constant feature of active colitis. Instead, the passage of hard stools suggests that by this criterion at least a sizeable proportion of colitics are constipated. The observation that the passage of hard stools was more common in patients with active than quiescent colitis suggests that in some patients hard stools are an index of disease activity. The existence of constipation in ulcerative colitis is supported by previous observations ${ }^{1-58-11}$ but the frequency with which this occurs and its relationship to the extent and activity of inflammation has never been assessed prospectively. A large survey of 450 patients published recently, has reported that only $3.5 \%$ of patients with colitis have constipation at the time of presentation. ${ }^{14}$ In this survey, the patients were asked to record their bowel habit as 'normal', 'diarrhoea', or 'constipation'. This form of assessment is unlikely to provide a clear picture, as most patients with colitis are often distracted by the frequent passage of blood and mucus. ${ }^{4}$ If frequency of defecation is the sole criterion used, then the occurrence of constipation will be overlooked.

The prevalence of important symptoms related to defecation has hitherto not been documented in patients with colitis. An urgent desire to defecate and a feeling of incomplete evacuation were reported by $80-90 \%$ of patients with active colitis and by $10-15 \%$ of patients with quiescent colitis. Tenesmus was reported by $63 \%$ of patients indicating that painful straining during evacuation is an important and frequent manifestation of active colitis. The preval- ence of these and other symptoms assessed were similar in patients with total and distal colitis, suggesting that they are related to an inflamed distal colon. Tests of anorectal function have shown that the rectum in patients with active colitis is hypersensitive $^{15}$ (unpublished data), poorly compliant ${ }^{16}$ and reacts excessively to intraluminal distension (unpublished data); features that could explain the symptoms of urgency and increased frequency of defecation.

The occurrence of nocturnal defecation and faecal incontinence invariably suggests active disease, as they were absent in patients with quiescent colitis. Eleven of 14 patients with incontinence were elderly women, and this group of the population has been shown to be particularly susceptible to incontinence. ${ }^{1718}$

Symptoms of increased bowel frequency, pain relieved by defecation, a feeling of incomplete evacuation and passage of mucus have been reported to favour a positive diagnosis of irritable bowel syndrome. ${ }^{19}$ As these symptoms are commonly present in colitics, we agree with others ${ }^{20}$ that it is not possible to distinguish patients with functional bowel disturbance from those with organic bowel disease on the basis of these symptoms alone.

We have recently shown that patients with active colitis void small volume stools frequently, and have stasis in the proximal colon and rapid transit through the rectosigmoid region, irrespective of the extent of colitis. ${ }^{12}$ Our present study shows how these changes in colonic function may be related to the symptoms of active disease, the proximal colonic stasis causing hard stools, and the irritable distal colon causing the more widely recognised frequent defecation, urgency, tenesmus, and a feeling of incomplete evacuation.

Dr S S C Rao is supported by a grant from the Special Trustees of the Former United Sheffield Hospitals.

\section{References}

1 Hurst AF. Ulcerative colitis. Guy's Hosp Rep 1935; 85: 317-55.

2 Bargen JA. In: Bargen JA, ed. Chronic ulcerative colitis. Springfield, Illinois: Charles C. Thomas, 1951.

3 Engel GL. Studies of ulcerative colitis. II. The nature of the somatic process and the adequacy of psychosomatic hypotheses. Am J Med 1954; 16: 416-33.

4 Shearman DJC. Ulcerative colitis. In: McLeod J, ed. Davidson's principles and practice of medicine. Edinburgh: Churchill Livingstone, 1985: 321-6.

5 Glickman RM. Inflammatory bowel disease: Ulcerative colitis and Crohn's disease. In: Petersdorf RG, Adams RA, Braunwald E, et al, eds. Harrison's principles of internal medicine. New York: McGraw-Hill Book Company, 1983: 1738-52. 
6 Truelove SC. Ulcerative Colitis. In: Weatherall DJ, Leadingham JGG, Warrell DA, eds. Oxford textbook of medicine. Oxford: Oxford University Press, 1985: 12, 107-12.

7 Cello JP, Meyer JH. Ulcerative colitis. In: Sleisenger MH, Fordtran JS, eds. Gastrointestinal disease. Pathophysiology, diagnosis, management. New York: WB Saunders, 1978: 1597-653.

$8 \mathrm{Sim} \mathrm{M}$, Brooke BN. Ulcerative colitis. A test of psychosomatic hypothesis. Lancet 1958; i: 125-6.

9 Lennard-Jones JE, Langman MJS, Jones, FA. Faecal stasis in proctocolitis. Gut 1962; 3: 301-5.

10 Lennard-Jones JE, Cooper GW, Newell AC, Wilson CWE, Avery Jones F. Observations on idiopathic proctitis. Gut 1972; 3: 201-6.

11 Jalan KN, Walker RJ, Prescott RJ, Butterworth STG, Smith AN, Sircus W. Faecal stasis and diverticular disease in ulcerative colitis. Gut 1970; 11: 688-96.

12 Rao SSC, Read NW, Brown C, Bruce C, Holdsworth $\mathrm{CD}$. Studies on the mechanism of bowel disturbance in ulcerative colitis. Gastroenterology (in press).

13 Truelove SC, Witts LJ. Cortisone in ulcerative colitis. Final report on a therapeutic trial. $\mathrm{Br}$ Med J 1955; ii: $1041-8$.
14 de Dombal FT, Myren J, Bouchier IAD, et al. Diagnosis of patients with inflammatory bowel disease - the value of clinical features. In: de Dombal FT, Myren J, Bouchier IAD, Watkinson G, eds. Inflammatory bowel disease-some international data and reflections. Oxford: Oxford University Press, 1986: 94-110.

15 Farthing MJG, Lennard-Jones JE. Sensitivity of the rectum to distension and the anorectal distension reflex in ulcerative colitis. Gut 1978; 19: 64-9.

16 Denis Ph, Colin R, Galmicke JP, et al. Elastic properties of the rectal wall in normal adults and in patients with ulcerative colitis. Gastroenterology 1979; 77: 45-8.

17 Ihre T. Studies on anal function in continent and incontinent patients. Scand J Gastroenterol 1974; 25: $1-80$.

18 Bannister JJ, Abouzekry L, Read NW. Effect of aging on anorectal function. Gut 1987; 28: 353-7.

19 Manning AP, Thompson WG, Heaton KW, Morris AF. Towards positive diagnosis of the irritable bowel. $\mathrm{Br}$ Med J 1978; 2: 653-4.

20 Isgar B, Harman M, Kaye MD, Whorwell PJ. Symptoms of irritable bowel syndrome in ulcerative colitis in remission. Gut 1983; 24: 190-2. 